\title{
INOVAÇÕES NA IMPLEMENTAÇÃO DA BASE NACIONAL COMUM CURRICULAR: UMA ANÁLISE SOBRE O BIOPARQUE DA AMAZÔNIA
}

\author{
Erique da Costa Fonseca ${ }^{1}$ \\ Yuri Breno da Silva e Silva²
}

\begin{abstract}
Resumo: O avanço tecnológico e a modernidade, ainda que assinalem mudanças vantajosas aos novos tempos, trouxeram retrocessos para a sociedade e o meio ambiente, ocasionando destruição e impactos irreversíveis à natureza. Frente a este cenário, ambientes naturais constituem-se como lócus privilegiados para 0 estabelecimento de políticas ambientais e manutenção da biodiversidade, como, por exemplo, os bioparques. Assim, por meio de observações e análises conceituais, 0 Bioparque da Amazônia, configura-se nesta proposta como um importante patrimônio natural, aliado ao desenvolvimento da Educação Ambiental no Amapá, já que se trata de um imensurável suporte de alcance didático, teórico, prático e metodológico enquanto projeção da vida sustentável. O local, nesse caso, pode vir a ser um lugar em que aprendizagens amplas sejam trabalhadas e desenvolvidas por professores da Educação Básica, com enfoque aos de Ciências da Natureza e suas tecnologias, quebrando os limites da formalidade e informalidade no campo educacional.
\end{abstract}

Palavras-chave: Educação Ambiental; Bioparque; Sustentabilidade; Amazônia.

Abstract: Technological advance and modernity, although they mark advantageous changes to the new times, have brought setbacks for society and the environment, causing destruction and irreversible impacts to nature. Faced with this scenario, natural environments constitute a privileged locus for the establishment of environmental policies and maintenance of biodiversity, such as bioparks. Thus, through observations and conceptual analyses, the Biopark of the Amazon is configured in this proposal as an important natural heritage, allied to the development of Environmental Education in Amapá, since it is an immeasurable support of didactic, theoretical, practical and methodological scope as a projection of sustainable life. The site, in this case, may become a place where extensive learning is worked on and developed by teachers of Basic Education, focusing on those of Nature Sciences and its technologies, breaking the limits of formality and informality in the educational field.

Keywords: Environmental Education; Biopark; Sustainability; Amazon.

\footnotetext{
${ }^{1}$ Biólogo. Especialista em Metodologia do Ensino de Ciências. Centro Universitário Leonardo da Vinci. E-mail: eriquecf@gmail.com, Link para o Lattes: http://lattes.cnpq.br/3965241605214419

2Biólogo. Mestre em Biodiversidade Tropical. Instituto Mapinguari. E-mail: yuribreno2@gmail.com. Link para o Lattes: http://lattes.cnpq.br/6968813342744962
} 


\section{Introdução}

Com o avanço das tecnologias e aumento da urbanização das cidades, as populações humanas tornaram-se distantes da natureza (GUIMARÃES; VASCONCELOS, 2006). Tal distanciamento tem trazido implicações negativas para a conservação da biodiversidade, tais como: o desmatamento, a extinção de espécies endêmicas e mudanças nos padrões climáticos globais (HENRIQUES et al., 2007). Além disso, surgem impactos também para o bemestar e a segurança humana, principalmente no que diz respeito a desigualdades sociais, soberania e segurança alimentar (ENCEA, 2019).

O declínio na extensão das áreas verdes, essenciais para a manutenção da vida, pois colaboram para o bem-estar social e melhoria em fatores climáticos, é o indicador maior de que o patrimônio natural se desmorona rapidamente. Logo, os impactos sobre os recursos naturais podem ser observados, em larga escala, em praticamente todos os biomas (ENCEA, 2019), em decorrência, principalmente, de atividades produtivas como: o agronegócio, atividade mineralógica, e o desenvolvimento desordenado das cidades (HENRIQUES et al., 2007). Ademais, a devastação ambiental que ameaça o bem-estar e o desenvolvimento das populações, incluem: processos de degradação do solo e desertificação, contaminação dos recursos hídricos, poluição atmosférica, mudanças climáticas e outros (ENCEA, 2019).

Devido a humanidade provocar grandes mudanças nos ecossistemas e, com isso, ser protagonista da crise ambiental em curso, os cientistas acreditam que o planeta entrou em uma nova era geológica, chamada de Antropoceno (ZALASIEWICZ et al, 2008). Entretanto, para reverter este quadro de colapso ambiental, faz-se necessário uma grande mudança no comportamento humano, começando com o resgate da conexão harmônica homem-natureza.

Atualmente, há uma série de iniciativas no mundo todo que busca harmonizar a relação do homem com a natureza. No Brasil, a Campanha "Um dia no parque", idealizada pela Rede Pró-Unidades de Conservação, objetiva demonstrar a importância de estar conectado com as áreas verdes e Unidades de Conservação, onde é possível praticar diferentes atividades ao ar livre. Ao mesmo tempo, a campanha busca sensibilizar a sociedade para um envolvimento nas questões relativas às áreas protegidas (MMA, 2010).

Exemplos internacionais podem ser encontrados no Japão, como a iniciativa denominada "banho de floresta" ou Shinrin-Yoku, que surgiu na década de 80 , e tem como objetivo aproximar o ser humano da natureza, buscando uma experiência que proporcione benefícios psicológicos, comportamentais e imunológicos (ICMBIO, 2017). Já no Nature For All, tem-se um "movimento global para inspirar o amor à natureza" (BLOMLEY; WALTERS, 2019), cuja base assenta-se na ideia de que quanto mais os seres humanos se conectam, experimentam e compartilham o gosto pela natureza, podem estimular mais pessoas a apoiarem ações de conservação do meio ambiente, 
seja no âmbito das UC, como também, nas demais áreas verdes (IMBACH; VIDAL, 2019).

De fato, há grandes oportunidades para promover, de forma inovadora, o consumo consciente e o desenvolvimento sustentável, entretanto, para criar o paradigma da sustentabilidade, é necessário que se estabeleça uma conexão do homem com a natureza de longo prazo (GUIMARÃES, 1995). É nesse contexto que a Educação para o Desenvolvimento Sustentável (EDS) surge como uma ferramenta inovadora a ser implementada na política socioambiental e na vida das pessoas (FIGUEIREDO, 2013).

A educação para a sustentabilidade (ES) oferece subsídios precisos a uma mudança dos padrões dominantes existentes. Ela introduz de forma gradual e permanente, uma nova racionalidade ambiental, integrando o ser humano, e a natureza de forma equilibrada (FIGUEIREDO, 2013). Como afirma CASTANHEIRA (2004) "a educação para a sustentabilidade é transformadora e, essa nova visão e postura do ser humano com o seu meio será eficaz na medida em que sua abrangência vai atingindo a totalidade dos grupos sociais". As iniciativas de ES buscam formar uma aliança global em favor do meio ambiente, pois, o desenvolvimento sustentável é um processo de aprendizagem social de longo prazo" (BEZERRA; BURSZTYN, 2000), mas que produz os seus efeitos na raiz do problema.

Nestas considerações, a educação para a sustentabilidade, surge como uma via pertinente neste processo de uma nova consciência sustentável, integrando os aspectos socioeconômicos com a questão ambiental, e estabelecendo um ponto de equilíbrio entre ambos, visto que:

A vida humana somente é possível quando integrada aos demais elementos da natureza, de onde provém o alimento e abrigo, além de todas as possibilidades de desenvolvimento tecnológico, onde o ser humano e a natureza são indistintos, unificados, porquanto advindos de uma criação única. (FIGUEIREDO, 2013, p. 843).

Assim, espaços como, parques silvestres, unidades de conservação, parques zoológicos e/ou botânicos, têm vantagem para implementar a ES como política pública. Muitos zoológicos têm passado por transformações profundas no seu funcionamento, saindo espaços de simples exposição da biodiversidade para ambientes onde os problemas ambientais estão contextualizados nos aspectos socioeconômicos, culturais. 


\section{Mudanças de Paradigmas nos Parques Zoológicos}

No que tange a questão ambiental, esta pode ser entendida como o exercício da cidadania, pois serve como parâmetros de projeção para uma sociedade solidária e democrática (ROOS; BECKER, 2012). Sendo assim, os espaços verdes (jardins, parques botânicos, zoológicos e bioparques), além de serem espaços que favorecem a conservação da biodiversidade, são lócus apropriados para o desenvolvimento da Educação Ambiental. Nessa perspectiva, para Moraes e Genebra (2016), estes ambientes são propícios para o desenvolvimento de atividades que possibilitem vislumbrar fenômenos, que antes foram apreendidos por meio de exposição teórica, serem analisados, vivenciados e estudados em espaços não formais de educação.

Considerando o distanciamento homem $x$ natureza e os consequentes danos à biodiversidade decorrentes de tal desconexão, propõem-se a utilização das áreas verdes, como parques urbanos, como recurso inovador em Educação Ambiental (CASTANHEIRA, 2004). Apesar de tais ambientes já serem utilizados dessa forma, há a necessidade de uma educação vivencial, onde o visitante estará imerso em uma experiência de reflexão e transformação (GUIMARÃES, 1995). Tais lugares são ambientes fundamentais para proporcionar a relação harmônica entre o meio natural e a sociedade, servindo ainda, como local de exposição de dinâmicas, práticas e vivências que assegurem um olhar sistêmico da questão ambiental e a construção de uma cultura saudável (FARINO; NASCIMENTO; IVANKKIO, 2014).

Além do mais, é necessário desmistificar a ideia que áreas verdes urbanas servem apenas como espaços atrativos ou mera diversão. É preciso entender que tais ambientes devem servir como locais de vivência, interação com o meio social e ponto de partida para incutir valores éticos e morais, pautados em uma educação para o desenvolvimento sustentável, aliando as práticas da eco pedagogia e os princípios da corresponsabilidade entre os povos (MORAES; GENEBRA, 2016). Nesse contexto, muitos parques urbanos e até zoológicos têm buscado transformar suas abordagens, aproximando-se da lógica de um Bioparque.

Entende-se por Bioparque, como o local onde fauna e flora são compreendidos enquanto elementos interdependentes. Desta maneira, todos os espaços que constituem um Bioparque não servem somente para a visitação e contemplação da natureza, mas, assumem também a tarefa de ser instrumento para promover uma reflexão crítica do agir humano e perceber que tudo o que existe, está interligado, devendo, portanto, haver um equilíbrio e harmonia entre todos os elementos (RAFAELA et al., 2016). 


\section{O Bioparque da Amazônia Arinaldo Gomes Barreto}

O Bioparque da Amazônia (Figura 1), localiza-se na Rodovia Juscelino Kubistchek, Distrito da Fazendinha, Cidade de Macapá, Estado do Amapá. Instalado em uma área de 107 hectares, o Bioparque é administrado pela Fundação Parque Zoobotânico Municipal Arinaldo Gomes Barreto, uma fundação pública municipal, vinculada à Prefeitura Municipal de Macapá. Segundo documentos históricos do próprio Parque, em 1977 a área era utilizada como um Campus Avançado de Pesquisa do Ângelo Moreira da Costa Filho em Convênio com a Universidade Federal do Rio de Janeiro. A partir de 1997, a Prefeitura de Macapá passou a administrar a área desde então, o espaço passou a receber a construção de instalações e recintos de animais silvestres.

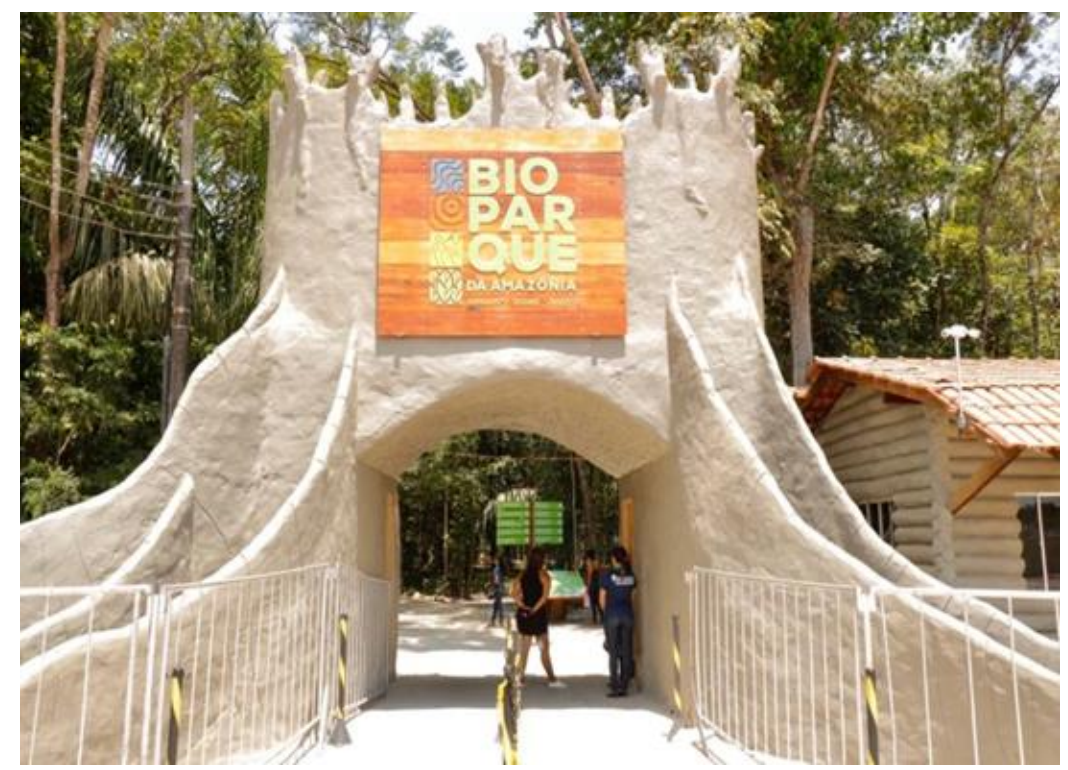

Figura 1: Entrada do Bioparque da Amazônia, Distrito da Fazendinha, Macapá-AP. Fonte: Prefeitura Municipal de Macapá/ Nayana Magalhães (2019).

A área do Bioparque é composta por um bloco contínuo e pouco alterado de floresta de terra firme, manchas de cerrado e área alagada que apresenta grande diversidade botânica, peculiar da região Amazônica. Além disso, o Bioparque está situado as margens da ressaca do Tacacá, que serve de refúgio para diversas formas de vida e apresenta grade importância na regulação do clima local e manutenção de Bacias Hidrográficas urbanas. Por apresentar um ecossistema bem preservado, o referido lugar representa um importante território para a construção de conhecimentos na área socioambiental.

O referido artigo baseia-se em pesquisas bibliográficas, para dá suporte e precisão para o pensamento transcrito no decorrer do trabalho. Foram consultadas obras literárias e artigos científicos consultados em sites acadêmico como o Scielo e Google Acadêmico, com a perspectiva de se analisar, entender e registrar os teóricos que discursam sobre os temas de 
Educação Ambiental, desenvolvimento sustentável e interdisciplinaridade, e artigos atualizados sobre os parques e bioparques.

O método qualitativo não se preocupa em resultados numéricos, mas deixa aberto um leque de interpretações para uma análise indutiva, que tem a incumbência do rigor, e de ser criterioso quanto as informações que se busca para a compreensão das mesmas, ou seja, o foco é a compreensão do contexto para a interpretações dos eventos. (DALFOVO et al, 2008)

A pesquisa documental, se caracteriza pela abordagem diversificada de fontes, se confundindo muitas vezes com a pesquisa bibliográfica, no entanto, ela aborda de maneira mais minuciosa, documentos que não poderiam constar como referencial teórico.

Deste modo, a metodologia utilizada neste trabalho buscou avaliar o potencial pedagógico e educacional nos atrativos e pontos específicos do Bioparque. Para tal, foram utilizadas pesquisas bibliográficas e observações diretas para identificar habilidades potenciais para serem desenvolvidas no Bioparque com jovens e crianças, em atendimento à Base Nacional Comum Curricular (BNCC) e à Política Nacional de Educação Ambiental (PNEA).

\section{O Bioparque da Amazônia como lócus de Educação Ambiental e sustentabilidade.}

O Bioparque, com todo seu aparato natural e administrativo, tem por objetivo fornecer entretenimento à comunidade de visitantes, aliado aos aspectos de projeção educativa e cultural; deve ainda servir como meio de divulgação potencial do turismo local. Em campo específico, o Bioparque da Amazônia apresenta uma série de atrativos com potencial de abordar inúmeros temas e desenvolver habilidades fundamentais no campo da pesquisa científica e a prática da Educação Ambiental, a saber:

O Bioparque funciona como abrigo para a fauna silvestre de Macapá, servindo como área de reprodução e alimentação dos animais que vivem livremente no seu interior, além disso, possui ainda animais mantidos em cativeiro. Este aspecto do local, alinha-se com a Política Nacional de Educação Ambiental (PNEA), à medida que serve de instrumento para o desenvolvimento de ações e práticas educacionais que promovam a sensibilização de toda uma coletividade, e sua participação efetiva na defesa e qualidade do meio ambiente (BRASIL, 1999), desenvolvendo habilidades relacionadas à conscientização ética de todos os seus visitantes.

Associada com a fauna silvestre, a flora nativa se apresenta em três ecossistemas distintos dentro do Bioparque, a Mata de Terra Firme, com floresta densa e árvores de grande porte, o Cerrado, com árvores de menor porte, gramíneas e arbustos, e os Campos Inundáveis, conhecidos no Amapá como ressacas, que são Zonas Úmidas que recebem a água das chuvas e possuem vegetação característica de palmeiras e plantas aquáticas. Tais espaços constituem instrumentos para o desenvolvimento de competências e 
habilidades relacionadas com o currículo de Ciências da natureza, por exemplo, a identificação das características sobre o modo de vida dos animais, desde sua alimentação até a sua interação com o meio ambiente. Ademais, em relação às áreas de ressacas, podem ser explorados a relação existente entre o ciclo hidrológico e a manutenção da vida das plantas e animais, bem como os aspectos relacionados ao clima da cidade ${ }^{6}$. (BRASIL, 2018).

Em relação ao Orquidário Municipal Terezinha Chaves - legado histórico do Município de Macapá e do Estado do Amapá - que serve como aparato para o desenvolvimento da EA, este configura-se como espaço ideal para o estudo da morfologia das plantas, com a identificação de suas principais partes, como raiz, caule e o local onde vivem.

Um ambiente de grande destaque no Bioparque é o Ecótono, que se caracteriza como uma área de transição entre ecossistemas ou biomas. O Bioparque abriga a transição entre três ecossistemas: mata de terra firmecerrado; cerrado-ressaca; mata de terra firme-ressaca. Este atrativo é um local essencial para 0 desenvolvimento de atividades ligadas à educação sustentável, pois mantém uma interface de interação entre os biomas presentes. Além disso, o Ecótono reforça o que preconiza o artigo 4ํㅡㄹ da Lei no 9795/99, que dispõe acerca do caráter interdisciplinar da EA, no qual alberga aspectos ecológicos e uma visão total do ambiente, como também as relações de interdependência da natureza e seres humanos (BRASIL, 1999).

Em relação ao caráter interdisciplinar, o Ecótono pode ser utilizado como exemplo para evidenciar a importância da cobertura vegetal ${ }^{7}$ na manutenção do ciclo da água, a proteção e conservação do solo e dos cursos de água, assim como a qualidade do ar que respiramos ${ }^{2}$, habilidades relacionadas ao senso crítico das transformações globais e seus impactos na natureza.

Sobre as atividades desenvolvidas no espaço verde, as trilhas interpretativas oferecem aos visitantes do Bioparque um contato direto com o meio ambiente, sendo explorado o aprendizado por meio da sensibilização (BRASIL, 2018, p.3-4; SANTOS; FLORES; ZANIN, 2017). Desse modo, a utilização das trilhas interpretativas tem como preocupação estabelecer conexões entre o homem e a natureza, constituindo-se como uma importante ferramenta para a conservação, preservação do patrimônio natural - como estabelece o artigo $13^{\circ}$ da PNEA - em que devam ser promovidas práticas educativas, voltadas à sensibilização da coletividade às questões ambientais, organização e participação dos homens na defesa da qualidade do meio ambiente (BRASIL, 1999). As trilhas interpretativas, podem estabelecer, ainda, conexão com a vida de animais e plantas, desde o seu nascimento, desenvolvimento e morte e a participação de animais e plantas nos processos relacionados a alimentação e geração de energia na natureza ${ }^{3}$.

Faz-se importante também ressaltar, que os jardins que existem no Bioparque da Amazônia são espaços preparados para atender ao público com algum tipo de necessidades especiais, haja vista que, o ambiente natural 
estimula os sentidos através de seus elementos táteis, sonoros e olfativos. Por outro lado, os jardins e áreas verdes são espaços que proporcionam o desenvolvimento de atividades que auxiliam na reflexão sobre a os danos da ação antrópica e seus impactos na dinâmica e funcionamento da biodiversidade ${ }^{9}$. Assim sendo, proporcionar o contato direto das pessoas com necessidades especiais (PNE) com a natureza, é incluí-las dentro do processo da Educação Ambiental no espaço da área verde urbana, integrando a natureza do Bioparque com as diferentes necessidades ${ }^{8}$ especiais, conforme estabelece a BNCC (BRASIL, 2018).

Dessa maneira, as ações ligadas à Educação Ambiental, seja em ambientes formais e não formais, devem ser um aporte integrado, contínuo e permanente em todos os níveis e modalidades do ensino (artigo 9o da Lei $\mathrm{n}$ 9795/99). Por conseguinte, incluir as PNE no âmbito do Bioparque é sensibilizar os ditos especiais em relação à natureza e sua importância, ao mesmo tempo, contribuindo para o desenvolvimento de seus aspectos emocionais, afetivos e cognitivos.

Por último, destaca-se o meliponário, que consiste em abrigar um ambiente dedicado à criação de abelhas sem ferrão da Amazônia. O referido equipamento ecológico destina-se, também, em aliar os processos econômicos e ambientais a serem explorados com a produção de mel, bem como, preservação e conservação da biodiversidade e o que estabelecem as políticas públicas ambientais, os princípios da sustentabilidade e o uso racional dos recursos naturais.

Destarte, a meliponicultura é uma alternativa de conservação ambiental e sustentabilidade, pois integra os aspectos de manejo sustentável ${ }^{8}$ com a agricultura artesanal e a economia verde, visando a conservação da fauna e flora $\mathrm{e} o$ envolvimento da sociedade em programas destinados à melhoria $\mathrm{e}$ ao controle efetivo sobre o meio ambiente e o trabalho, bem como, as repercussões do processo produtivo no meio ambiente e as soluções de problemas ambientais (artigo $3^{\circ}$ da Lei n. 9795/99).

Nesse sentido, pensar as ações desenvolvidas pelo parque, bem como aliar os espaços existentes em vista de uma educação para a sustentabilidade, requer fazer uma conexão com a Política Nacional e Educação Ambiental, bem como os dispositivos norteadores da Educação Básica no Brasil. Por isso, nesta produção procurou-se direcionar o uso de cada espaço do Bioparque aliando-se a Base Nacional Curricular Comum - BNCC, conforme a Tabela 1 a seguir: 
Tabela 1 Relação dos Equipamentos do Bioparque com as Habilidades da BNCC de Ciências da Natureza.

\begin{tabular}{|c|c|c|c|}
\hline \multirow[b]{2}{*}{ ATRATIVOS } & \multirow[b]{2}{*}{ TEMA } & \multicolumn{2}{|c|}{$\begin{array}{l}\text { CÓDIGO DAS HABILIDADES DE CIÊNCIAS DA } \\
\text { NATUREZA E SUAS TECNOLOGIAS - BNCC }\end{array}$} \\
\hline & & $\begin{array}{c}\text { ENSINO } \\
\text { FUNDAMENTAL }\end{array}$ & ENSINO MÉDIO \\
\hline \multirow{3}{*}{ Ecótono } & Ecologia & EF02Cl04/EF07Cl071 & EM13CNT2039 $^{9}$ \\
\hline & Clima & EF04CI03/EF08Cl14 & EM13CNT102 \\
\hline & Fauna & EF03Cl046/EF04Cl0533 & EM13CNT202 \\
\hline Orquidário & Flora & $\mathrm{EF} 02 \mathrm{CILO6}^{7}$ & EM13CNT206 $^{4}$ \\
\hline \multirow{4}{*}{$\begin{array}{l}\text { Trilhas } \\
\text { Interpretativas }\end{array}$} & Fauna & EF03CI04/EF04CI05 & EM13CNT202 \\
\hline & Flora & EF02CIL06 & EM13CNT206 \\
\hline & Clima & EF04CI03/EF08Cl14 & EM13CNT102 \\
\hline & Tempo/Espaço & EF01CI05 & EM13CNT204 \\
\hline \multirow{2}{*}{ Jardins } & Flora & EF02CIL06 & EM13CNT2065 \\
\hline & Clima & EF04CI03/EF08Cl14 & EM13CNT102 \\
\hline \multirow{4}{*}{ Meliponário } & Alimentação & EF05Cl08 & EM13CNT307-308 \\
\hline & Fauna & EF03CI04/EF04CI05 & EM13CNT202 \\
\hline & $\begin{array}{l}\text { Recursos } \\
\text { Naturais }\end{array}$ & EF05Cl05/EF05Cl03² & EM13CNT106 $^{8}$ \\
\hline & $\begin{array}{l}\text { Matéria e } \\
\text { Energia }\end{array}$ & EF02CI02/EF08Cl01 & EM13CNT1019 \\
\hline
\end{tabular}

Fonte: Adaptado da Base Nacional Curricular Comum - BNCC (Brasil, 2018).

Nestas considerações, o tema acerca da Educação Ambiental e o manejo socioeconômico aparecem entre as competências gerais da Base Nacional Comum Curricular, de maneira que a sustentabilidade pressupõe 0 cuidado planetário, de si mesmo e dos outros; Além disso, a BNCC pondera que a Educação Ambiental está relacionada com o agir pessoal e coletivo com autonomia, responsabilidade, flexibilidade, resiliência, tomada de decisões com base em princípios éticos, democráticos, inclusos, sustentáveis e solidários de todos (competência 10 da BNCC).

\section{Conclusões}

Portanto, com a realização desta pesquisa, conclui-se que o Bioparque da Amazônia configura-se como uma importante ferramenta no desenvolvimento da Educação Ambiental no Estado do Amapá, pois, apresenta, dentro de sua estrutura, atrativos que permitem o desenvolvimento de atividades voltadas para a sensibilização ambiental dos visitantes, a aquisição de habilidades voltadas para a preservação e conservação na natureza, bem como, apresenta características voltadas para a divulgação cientifica e sociocultural da região amazônica.

Em relação ao Programa de Educação, este é de suma importância para o equipamento, pois funciona como a "carta magna", do Bioparque, esboçando não só as políticas públicas e ambientais da administração, como 
também, delineia os princípios ambientais locais e universais praticados e norteia as ações educativas no âmbito da natureza contextualizada com os aspectos sociais, políticos e econômicos do Estado, contribuindo assim, para uma nova consciência ambiental, baseada na solidariedade entre os povos e corresponsabilidade planetária, buscando assegurar o futuro das gerações vindouras.

Por último, em relação à Educação Básica, o Bioparque contempla quase que $80 \%$ de todas as competências e habilidades do currículo de Ciências da Natureza e suas tecnologias, seja a nível do ensino fundamental quanto o ensino médio. Além de tudo, consegue aliar a educação formal aos aspectos da educação informal, contribuindo na formação de cidadãos conscientes do seu dever e papel ambiental, frente aos impactos e desastres causados pela ação antrópica.

\section{Agradecimentos}

Ao Centro Universitário Leonardo da Vinci (UNIASSELVI) por tornar possível a especialização do autor.

Á Professora Nazaré da Silva e Silva, por suas valiosas contribuições na revisão gramatical deste artigo.

\section{Referências}

BEZERRA, M. C. L.; BURSZTYN, M. (cood.). Ciência e Tecnologia para o desenvolvimento sustentável. Brasília: Ministério do Meio Ambiente e dos Recursos Naturais Renováveis: Consórcio CDS/ UNB/ Abipti, 2000.

BLOMLEY, T; WALTERS, G. (eds). A Landescap for Everyone: integrating rights-based landscape governance approaches. Gland. Switzerland: IUCN. 2019. p.86.

BRASIL. Lei no 9795 de 27 de abril de 1999. Dispõe sobre a Educação Ambiental, Institui a Política Nacional de Educação Ambiental e dá outras providências. Brasília, DF, 1999.

BRASIL. Instituto Chico Mendes de Biodiversidade. ICMBIO. Relatório Diálogos ICMBIO: saúde, parques e reservas - banho de floresta. Brasília: DF, 2017.

BRASIL. Ministério da Educação. Secretaria de Educação Básica. Base Nacional Comum Curricular - BNCC. Brasília: DF, 2018.

BRASIL. Ministério do Meio Ambiente. Diretrizes para Estratégia Nacional de Comunicação e Educação Ambiental em Unidades de Conservação ENCEA. Brasília, DF, 2019. 
BRASIL. Ministério do Meio Ambiente. Secretaria de Articulação Institucional e Cidadania Ambiental. Programa das Nações Unidas para o Desenvolvimento. Projeto BRA/00/011. Contrato n. $-2010 / 000367$. Termo de Referência n.. 133876. Documento descritivo contendo proposta de campanha sobre Educação Ambiental e mudanças climáticas, incluindo estratégia de execução. Brasília, DF, 2010.

CASTANHEIRA, D.B.A. Educação Ambiental como foco do turismo pedagógico. Revista Ciência \& Conhecimento. v. 1, n.4, p. 79-92. Nov. 2004.

DALFOVO, M. S; LANA, R. A; SILVEIRA, A. Métodos quantitativos e qualitativos: um resgate teórico. Revista Interdisciplinar Científica Aplicada, Blumenau, v.2, n.4, p.01- 13, Sem II. 2008.

FARINO, C.L; NASCIMENTO, E.L; IVANIO, R. Avaliação da Prática de Educação Ambiental no Zoológico Bosque Guarani no Município de Foz do Iguaçu - Paraná. Trabalho de Conclusão de Curso. P.66. Universidade Tecnológica do Paraná. Medianeira, PR, 2014.

FIGUEIREDO, R.A. Educação para a Sustentabilidade: novidade ou resgate de significado?. Revista eletrônica Polêmica. v.12. n. 2. p. 830-845. Abr/Jun de 2013.

GUIMARÃES, M. A dimensão ambiental na educação. Campinas, São Paulo: Papirus, 1995.

GUIMARÃES, M. A Formação de Educadores Ambientais. Campinas, São Paulo: Papirus, 2007.

GUIMARÃES, M; VASCONCELOS, M. M.N. Relação entre Educação Ambiental e Ciências na Complementariedade dos Espaços Formais e não Formais de Educação. Revista Educar. n.27, p. 1477-162. Editora UFPR, 2006.

HENRIQUES, R. et al. Educação Ambiental: aprendizes de sustentabilidade. Cadernos SECAD. V. 1. Secretaria de Educação continuada, alfabetização e diversidades. Ministério da Educação. Brasília: DF, 2007.

IMBACH, A.A; VIDAL, A. How Inter-institutional Net Works Transform Landescapes: lessons fron latin America on advancing forest landscape restoration. Gland. Switzerland: IUCN. 2019. p.94.

MORAES, L.E; GENEBRA, M.J.F. O Ensino de Física Ambiental: análise do potencial pedagógico de espaços não formais de educação. In: SOUZA, R.D; ANGOTTI, J.A.P (org). Reflexão em Ensino de Ciências. v.1, p. 10-20. Curitiba: Atena, 2016.

RAFAELA, B. et al. O Parque Zoobotânico Arruda Câmara e a Alfabetização Ecológica do Cidadão-Turista. Revista Campo do Saber. v. 2, n. 2. Jul/Dez de 2016. p. 130-143. 
ROOS, A.; BECKER, E.L.S. Educação Ambiental e Sustentabilidade. Revista Eletrônica em Gestão, Educação e Tecnologia Ambiental. v.5. n.5. 2012. p. 857-866.

SANTOS, M.C; FLORES, M.D; ZANIN, E.M. Trilhas Interpretativas como Instrumento de Interpretação, Sensibilização e Educação Ambiental na APAE de Erechim/RS. Vivências: Revista Eletrônica de Extensão da URI. Vol. 7, n. 13, p. 189-197. Outubro/2017.

ZALASIEWICZ, J; BARRY, T.L; WILLIAMS, M.; CANTRIL, D.J. Are We Now Living in the Antropocene?. GSA Today. Vol. 8, n. 2, p. 4-8. Fevereiro, 2008. Disponível em: <https://www.researchgate.net/publication/235697307>. Acesso em: 27 de agosto de 2019. 